\title{
The Allied Health Work Readiness Study: Identifying Personal Characteristics Signalling Work Readiness in Allied Health Students
}

Maxine O'Brien

Darling Downs Health, obrien.maxine@gmail.com

Kelli Troy

Darling Downs Health, Kelli.Troy@health.qld.gov.au

Jayne Kirkpatrick

Darling Downs Health, Jayne.Kirkpatrick@health.qld.gov.au

Follow this and additional works at: https://nsuworks.nova.edu/ijahsp

Part of the Health Services Research Commons, Industrial and Organizational Psychology Commons, Interprofessional Education Commons, Organizational Behavior and Theory Commons, and the Other Educational Administration and Supervision Commons

\section{Recommended Citation}

O'Brien M, Troy K, Kirkpatrick J. The Allied Health Work Readiness Study: Identifying Personal Characteristics Signalling Work Readiness in Allied Health Students. The Internet Journal of Allied Health Sciences and Practice. 2020 Jan 01;18(1), Article 5.

This Manuscript is brought to you for free and open access by the College of Health Care Sciences at NSUWorks. It has been accepted for inclusion in Internet Journal of Allied Health Sciences and Practice by an authorized editor of NSUWorks. For more information, please contact nsuworks@nova.edu. 


\title{
The Allied Health Work Readiness Study: Identifying Personal Characteristics Signalling Work Readiness in Allied Health Students
}

\begin{abstract}
Purpose: Clinical placements associated with university degrees for the allied health professions aim to support the preparation of students for post graduate employment through the practical application of theoretical constructs. However, employers recognise that a range of generic skills and attributes outside of technical and academic achievement impact of work readiness. Allied health clinical educators within Darling Downs Health (DDH) sought to identify these generic characteristics, and their relative importance, with a view to further supporting the work readiness of students completing placements in the district. Method: The study utilised the knowledge and experience of allied health clinical educators, experienced clinical supervisors, and allied health directors, to explore the characteristics thought to be related to work readiness. Participants completed a brief demographic questionnaire before participating in one of three groups which employed the Nominal Group Technique to seek answers to the research question "What do you believe are the most important personal characteristics signalling work readiness in allied health students?" Results: Data were analysed by group and then overall, resulting in a complete list of 103 characteristics raised, 37 of which were judged as among the "most important" by study participants. Analysis revealed six characteristics which were identified and voted as among the most important by each independent group. Personal insight and self-awareness rose to the top of the list of most important characteristics, with 16 of the 18 participants voting for this characteristic, and a mean importance rating of 9.3 of a possible 10. Resilience was second on this list, followed by communication skills, organisational skills, lifelong learning, and professionalism. A further nine characteristics were selected by two of the three groups, while an additional 22 characteristics were raised and voted as among the most important by members of a single group. Conclusions and Recommendations: We believe that these results may be of interest to allied health students, allied health staff, universities and training organisations, recruiters, and managers. It is our hope that identification of these characteristics may also lead to the development of targeted education and support programs within DDH to assist students' growth in these areas.
\end{abstract}

\section{Author Bio(s)}

Maxine O'Brien BSc Hons (Psych) PhD MAPS, has enjoyed a varied career as a psychologist including clinical, teaching, supervision and research roles. In addition to private practice and university commitments, Maxine's current roles include that of Senior Psychologist and DDH Acting Research Fellow.

Kelli Troy Grad Dip Applied Science (Applied Psych) Assoc. MAPS, has had an extensive career in psychology in both clinical and non-clinical roles. She currently works as Psychology Clinical Educator within Darling Downs Health. Kelli has long been interested in supporting new graduates to successfully transition into the workplace.

Jayne Kirkpatrick BSc MNutDiet GDTL, studied human nutrition and dietetics at Sydney University and has worked as a dietitian, nutrition project coordinator and clinical educator in Australia and the UK over the past 25 years. Jayne's has a keen interest in education for patients, students and health professionals.

\section{Acknowledgements}

The authors would like to thank the participants in this study for their kind generosity in dedicating precious time and thought to this task. 


\title{
IIVAHSP ${ }^{\mathrm{m}}$ \\ The Internet Joumnal of Allied Health Sciences and Practice \\ Dedicated to allied health professional practice and education \\ Vol. 18 No. 1 ISSN 1540-580X
}

\section{The Allied Health Work Readiness Study: Identifying Personal Characteristics Signalling Work Readiness in Allied Health Students}

\author{
Maxine O'Brien \\ Kelli Troy \\ Jayne Kirkpatrick
}

Darling Downs Health

Australia

\begin{abstract}
Purpose: Clinical placements associated with university degrees for the allied health professions aim to support the preparation of students for post graduate employment through the practical application of theoretical constructs. However, employers recognise that a range of generic skills and attributes outside of technical and academic achievement impact of work readiness. Allied health clinical educators within Darling Downs Health (DDH) sought to identify these generic characteristics, and their relative importance, with a view to further supporting the work readiness of students completing placements in the district. Method: The study utilised the knowledge and experience of allied health clinical educators, experienced clinical supervisors, and allied health directors, to explore the characteristics thought to be related to work readiness. Participants completed a brief demographic questionnaire before participating in one of three groups which employed the Nominal Group Technique to seek answers to the research question "What do you believe are the most important personal characteristics signalling work readiness in allied health students?" Results: Data were analysed by group and then overall, resulting in a complete list of 103 characteristics raised, 37 of which were judged as among the "most important" by study participants. Analysis revealed six characteristics which were identified and voted as among the most important by each independent group. Personal insight and self-awareness rose to the top of the list of most important characteristics, with 16 of the 18 participants voting for this characteristic, and a mean importance rating of 9.3 of a possible 10. Resilience was second on this list, followed by communication skills, organisational skills, lifelong learning, and professionalism. A further nine characteristics were selected by two of the three groups, while an additional 22 characteristics were raised and voted as among the most important by members of a single group. Conclusions and Recommendations: We believe that these results may be of interest to allied health students, allied health staff, universities and training organisations, recruiters, and managers. It is our hope that identification of these characteristics may also lead to the development of targeted education and support programs within DDH to assist students' growth in these areas.
\end{abstract}

Keywords: allied health, work readiness, nominal group technique, qualitative research, personal insight, allied health graduates, allied health recruitment 


\section{INTRODUCTION}

While academic achievement and technical ability have traditionally been used to predict success in the workplace, modern day employers also recognise the importance of a range of generic skills and attributes that impact on the individual's work performance..$^{1-3}$ The degree to which graduates possess these generic attributes, enhancing "work readiness", is seen as indicative of the graduate's potential job performance, success, promotion, and career advancement. ${ }^{4}$ While there is a lack of consensus about the specific list of attributes that comprise work readiness, there is a growing demand for graduates to possess a wide-range of non-technical skills and knowledge necessary for effective participation in the workforce.,5

Caballero and colleagues developed the Work Readiness Scale, which is designed to measure the attributes and characteristics of work readiness identified in their earlier research using generic "graduate," and "graduate nurse," samples.5,6 Their findings identified four factors within this construct : personal characteristics (personal skills, self-direction, selfknowledge, adaptability, flexibility), organisational acumen (professionalism, work ethic, ethical judgement, social responsibility, global knowledge, motivation, lifelong learning/self-direction), work competence (organisational ability, critical thinking, problem-solving, creativity/innovation), and social intelligence (teamwork/collaboration, interpersonal/social skills, adaptability, communication skills). These authors argue that the high-risk environment, heavy workloads, high turnover, and rate of burnout, may make the identification of work readiness attributes of particular interest to the health industry. ${ }^{6}$ Given the unique demands on health professionals, it was also recognised that these attributes may differ for this group, prompting efforts to explore work readiness among graduate nurses, ${ }^{6,7}$ However, no published research investigating work readiness among allied health professionals (e.g. physiotherapists, psychologists, occupational therapists) could be identified.

Much of the research into work readiness to date has been conducted using graduate or employer samples, representing a further gap in the extant literature. While this is a valid approach to the question, the voices of staff tasked with overseeing student placements are yet to be heard. Among the allied health professions, hospital staff including clinical educators and clinical supervisors are typically tasked with providing on-the-job training, mentoring, and observations of the student's performance during their final pre-graduate experiences. Within Darling Downs Health (DDH), these positions are held by individuals who are senior members of the student's chosen profession, who allocate significant time to observing and developing students in preparation for graduation into the profession. These staff members hold specific experience and insights into the performance and development of various students over time, which may be a valuable addition to the work readiness discussion.

The current study aims to identify the personal characteristics of allied health students which contribute to work readiness, and to gain insights into which of these characteristics may be considered most important when embarking on an allied health career. This question has become increasingly important to DDH Allied Health Clinical Educators, who aim to utilise this knowledge to identify target characteristics which may be supported or modified to enhance work readiness in allied health students whilst on placement. Once identified, activities and experiences designed to enhance the target characteristic(s) will be introduced within $\mathrm{DDH}$, in the hope of enhancing student preparedness for transition into the workplace.

\section{METHODS AND MATERIALS \\ Setting}

The study was conducted with staff employed within a regional hospital in South-East Queensland, Australia.

\section{Participants}

The study sought to employ the collective wisdom and experience of allied health clinical educators, experienced clinical supervisors, and allied health directors, to explore the characteristics thought to be related to work readiness in DDH. Suitable participants for this purposive sample were invited to participate in the study by members of the research team. Allied health professions represented in the sample include psychology, nutrition and dietetics, speech pathology, occupational therapy, physiotherapy, and social work.

\section{Group One: Allied Health Directors \& AH Workforce Development Officer, $(n=7)$}

Group one participants included directors of six allied health professions and an allied health workforce development officer. These positions frequently take responsibility for staff selection and recruitment and are called upon to provide advice and intervene should there be concerns about the performance of staff and students within their respective professions. Six allied health professions were represented in this group.

\section{Group Two: Clinical Supervisors $(n=5)$}

Group two participants included experienced clinical supervisors of students on placement. These staff members are responsible for the day to day supervision of students on placement. Supervisors provide one-on-one and/or group supervision and training to students and are responsible for overseeing the student's clinical and professional development to ensure safe, ethical clinical practice. Five allied health professions were represented in this group. 
Group Three: Allied Health Clinical Education Support Officers (CESO's) \& Clinical Supervisors $(n=6)$

Group three was made up of four clinical educators and two clinical supervisors. Clinical educators are responsible for organising and supporting student placements within their allied health profession. They are the first contact point should there be concerns about the students' progress or the supervisory relationship. They also liaise with the university involved to remediate any concerns. Five allied health professions were represented in this group.

Table 1. Summary of participant groups

\begin{tabular}{|l|l|l|l|l|}
\hline Group & Description & $\mathbf{N}$ & $\begin{array}{l}\text { Experience as an AH } \\
\text { professional }\end{array}$ & $\begin{array}{l}\text { Experience } \\
\text { training/supervising students } \\
\text { \& new graduates }\end{array}$ \\
\hline 1 & $\begin{array}{l}\text { AH Directors \& AH Workforce } \\
\text { Development Officer }\end{array}$ & 7 & $\begin{array}{l}\text { Range }=9-29 \text { years } \\
\text { Approx. Mean }=21 \text { years }\end{array}$ & $\begin{array}{l}\text { Range }=8-25 \text { years } \\
\text { Approx. Mean }=15 \text { years }\end{array}$ \\
\hline 2 & Clinical Supervisors & 5 & $\begin{array}{l}\text { Range }=6-27 \text { years } \\
\text { Mean }=16 \text { years }\end{array}$ & $\begin{array}{l}\text { Range }=5-16 \text { years } \\
\text { Mean }=9 \text { years }\end{array}$ \\
\hline 3 & $\begin{array}{l}\text { Clinical Educators }(n=4), \text { plus } \\
\text { Clinical Supervisors }(n=2)\end{array}$ & 6 & $\begin{array}{l}\text { Range }=14-30 \text { years } \\
\text { Mean }=21 \text { years }\end{array}$ & $\begin{array}{l}\text { Range }=3-25 \text { years } \\
\text { Mean }=13 \text { years }\end{array}$ \\
\hline
\end{tabular}

\section{Procedure}

Following the provision of informed consent, participants were provided with a brief questionnaire to collect the demographic information contained in Table 1. An information sheet specifying the question to be posed to the group and describing the group process was also provided at recruitment.

The Nominal Group Technique was utilised for data collection. ${ }^{8}$ On arrival, participants were given a copy of the meeting agenda, a sheet of paper to list ideas generated at Step One, and a rating sheet designed to collate responses at Step Four. Groups proceeded as follows:

1. Silent generation of ideas in writing. Members were asked to spend 5 minutes silently and independently listing their ideas in response to the research question "What do you believe are the most important personal characteristics signalling work readiness in allied health students?". Resilience was provided as an example characteristic found in the extant literature. Ideas were noted in brief phrases and written in the order in which they were generated on the sheet provided.

2. Recorded round-robin listing of ideas on chart. Each group member was asked to read one of their ideas in turn, with the scribe writing each idea on a flip chart as it was read. All ideas were assigned a number and recorded as presented without discussion. If an idea had been brought up by another group member, the participant was asked to move on to the next one on their list. The procedure continued around the table enough times for each group member to complete their list.

3. Discussion of each idea for clarification and evaluation. Each idea on the chart was discussed in order. The leader read each aloud in turn, and asked the group for questions, statements or clarification, or any statements of agreement or disagreement members would like to make. This section was audiotaped.

4. Vote on priorities: silent, independent. The leader read the question aloud again and asked the group members to select from the entire list, the seven most important factors identified. Members were asked to rate the factors from no importance (1) to high importance (10) on the ratings sheet provided. It was permissible to have one or more factors of equal importance.

-Morning/Afternoon Tea- The group leader collected the rating sheets and computed the group's cumulative rating for each item during this time. Ratings were presented on the whiteboard for the final step.

5. Presentation of group consensus and final discussion. The cumulative group ratings for each item and final rankings were presented to the group for discussion. The purpose of this discussion was for clarification, specifically to:

- examine inconsistent voting patterns, and

- provide an opportunity to discuss any items which were perceived by members of the group as receiving too many or too few votes. This section was audiotaped.

\section{Analysis Strategy}

Data collected from the groups included:

1. Step One individual responses to the question, noted on data collection form.

2. Steps Two and Three responses, listed on chart.

3. Audiotaped discussion of characteristics during Step Three, transcribed verbatim for analysis.

4. Step Four individual rating sheets, and the results of group consensus.

5. Audiotaped discussion at Step 5, transcribed verbatim for analysis. 
A summary of the outcomes by group and as an aggregated sample was achieved using descriptive statistics. Ranking was achieved by considering 1) the number of participants/groups raising the characteristic, then 2) the mean ranking assigned by the participant/group under analysis. Qualitative analysis of the transcribed audiotapes was achieved using thematic analysis, with themes exemplified by verbatim quotes from the study participants. These data allowed for more comprehensive descriptors of the characteristics chosen. Qualitative descriptions were also used to facilitate decisions by the research team regarding characteristics identified by more than one group which were synonymous in meaning, and therefore suitable to be analysed together in the combined group sample.

Note. At the time of analysis, the intended meaning of group three's characteristic number 10 - "Insight" and number 22 "the ability to self-reflect [on] actions and behaviours" were considered synonymous. Group transcripts and written materials were reviewed and the options to satisfactorily represent the group's data were discussed by research team members. To redress this issue, the following correction was made: a count of all individual Group 3 participants who had selected either item 10 or 22 was adopted, along with their assigned rating. One participant selected both items at Step four, so a mean of the two scores assigned by this individual was used in the analysis. To ensure the aggregated, three-group results would not be significantly impacted by our decision to combine these items, a secondary analysis which excluded Group Three and utilised Group One and Two data only, was conducted. This analysis revealed no significant change in the study results based on a two-group sample, with Insight and Self-awareness being the number one characteristic identified in both the two group $(n=$ $9 ; \bar{x}=9.5)$, and three group analyses $(n=16 ; \bar{x}=9.3)$. Similarly, adoption of either one or the other of these Group Three items resulted in the same aggregate group results. While the study's broader aggregate results were therefore not significantly impacted by the correction, the decision to correct the data did elevate this factor to number one for this individual group. Without the correction, the number one result for this group would have been resilience. The data suggests that this correction leads to a more accurate reflection of the group's intent.

\section{FINDINGS AND DISCUSSION}

\section{Factors Identified and Selected as Amongst the Most Important by the Individual Groups}

The three groups generated a total of 103 personal characteristics which they believed signal work readiness in allied health students, many of which overlapped or were synonymous with those identified by other groups in the study. The top ten characteristics for each group are presented as Table 2. Because of space restrictions, further discussion of the individual group data will be put aside in favour of a focus on the combined group results.

Table 2. Top Ten Characteristics Rated as Most Important by Individual Groups

\begin{tabular}{|c|c|c|}
\hline Group One & Group Two & Group Three \\
\hline Resilience & Ability to self-reflect and self-awareness & $\begin{array}{l}\text { Insight and the ability to self-reflect on } \\
\text { actions and behaviours }\end{array}$ \\
\hline Insight and self-awareness & $\begin{array}{l}\text { Communication skills and adapting } \\
\text { communication to others }\end{array}$ & Resilience - in personal and work life \\
\hline Emotional stability and regulation & Enthusiasm & Sense of humour \\
\hline Ability to communicate with all people & $\begin{array}{l}\text { Self-management skills - prioritising } \\
\text { workload and work day organisation }\end{array}$ & $\begin{array}{l}\text { Active, self-directed learner/Willingness } \\
\text { to learn }\end{array}$ \\
\hline Adaptable to circumstances - flexible & Clinical reasoning & $\begin{array}{l}\text { Emotional maturity - to cope and to } \\
\text { respond to patients }\end{array}$ \\
\hline Business minded & Adaptability/flexibility & $\begin{array}{l}\text { Professionalism - integrity, } \\
\text { accountability, time management, } \\
\text { respect }\end{array}$ \\
\hline "Balanced" confidence & $\begin{array}{l}\text { Active lifelong learning and intellectual } \\
\text { curiosity }\end{array}$ & $\begin{array}{l}\text { Ability to connect with patients - } \\
\text { empathy and boundaries-appropriate } \\
\text { sharing }\end{array}$ \\
\hline Growth mindset & Resilience & Reliability - managing caseload/tasks \\
\hline Professionalism & $\begin{array}{l}\text { Core knowledge appropriate to level of } \\
\text { training }\end{array}$ & $\begin{array}{l}\text { Excellent communication skills - verbal } \\
\text { and written }\end{array}$ \\
\hline Understanding contexts & $\begin{array}{l}\text { Openness to seeking and responding to } \\
\text { feedback }\end{array}$ & $\begin{array}{l}\text { Recognise stress and strategies to } \\
\text { manage (self-care) }\end{array}$ \\
\hline
\end{tabular}

\section{Factors Independently Identified and Selected as Amongst the Most Important by all Three Groups}

As Table 3 reveals, there were six characteristics which were independently identified, and subsequently rated as among the most important, by all three groups. The independent nature of the groups, and the variety of specialist areas represented by the group compositions (i.e. allied health directors, clinical educators and clinical supervisors), suggests that this list of six characteristics may represent an important insight into work readiness attributes among allied health students. Results for the number one characteristic identified, insight and self-awareness, are particularly strong. 
Table 3. Combined Group Results -Ranking of Characteristics Identified as of Most Importance to Work Readiness.

\begin{tabular}{|c|c|c|c|}
\hline Rank & $\begin{array}{l}\text { Groups } \\
\text { Included }\end{array}$ & Count/mean & Characteristic \\
\hline \multicolumn{4}{|c|}{ Rated among most important by all three groups } \\
\hline 1 & $1,2,3$ & $16 / 9.3$ & Insight and self-awareness \\
\hline 2 & $1,2,3$ & $14 / 8.8$ & Resilience \\
\hline 3 & $1,2,3$ & $9 / 9.6$ & Communication skills and adapting communication to others (verbal and written) \\
\hline 4 & $1,2,3$ & $7 / 7.3$ & Basic organisational skills - prioritising workload and work day organisation \\
\hline 5 & $1,2,3$ & $6 / 8.5$ & Commitment to lifelong learning \\
\hline 6 & $1,2,3$ & $5 / 8.7$ & Professionalism \\
\hline \multicolumn{4}{|c|}{ Rated among most important by two of the three groups } \\
\hline 7 & 1,3 & $7 / 9.2$ & Emotional stability/maturity and emotional regulation \\
\hline 8 & 1,2 & $6 / 8.9$ & Adaptability/flexibility \\
\hline 9 & 2,3 & $3 / 10$ & Empathy \\
\hline 10 & 2,3 & $3 / 8$ & Recognise stress and have strategies to manage (self-care) \\
\hline $11^{*}$ & 1,2 & $3 / 7.8$ & Sound technical and clinical knowledge appropriate to level of training \\
\hline $11^{*}$ & 1,2 & $3 / 7.8$ & "Balanced" confidence \\
\hline 12 & 2,3 & $2 / 9.5$ & Seeking and responding to feedback - admitting when you don't know \\
\hline 13 & 2,3 & $2 / 8.5$ & Intrigue and interest/curiosity \\
\hline 14 & 1,2 & $2 / 7$ & Ability to work inter-professionally \\
\hline \multicolumn{4}{|c|}{ Rated among most important by one group only } \\
\hline 15 & 1 & $4 / 8.5$ & Business minded \\
\hline 16 & 3 & $4 / 8$ & Sense of humour \\
\hline 17 & 2 & $3 / 8.3$ & Enthusiasm \\
\hline 18 & 2 & $3 / 7.7$ & Clinical reasoning \\
\hline 19 & 1 & $2 / 9.5$ & Growth mindset \\
\hline $20^{*}$ & 1 & $2 / 9$ & Understanding contexts \\
\hline $20^{*}$ & 3 & $2 / 9$ & Sound, stable personality constructs \\
\hline 21 & 1 & $2 / 8$ & Desire for continuous improvement - able to stop and review \\
\hline $22^{*}$ & 1 & $1 / 10$ & "Considered" initiative \\
\hline $22^{*}$ & 1 & $1 / 10$ & Team focus / team player \\
\hline $22^{*}$ & 1 & $1 / 10$ & Mindset for contribution to service rather than "What's in it for me?" \\
\hline $22^{*}$ & 2 & $1 / 10$ & Self-initiative \\
\hline $22^{*}$ & 3 & $1 / 10$ & Patient focus/values \\
\hline $22^{*}$ & 3 & $1 / 10$ & Critical thinking \\
\hline $23^{*}$ & 1 & $1 / 9$ & Optimism \\
\hline $23^{*}$ & 2 & $1 / 9$ & Personable \\
\hline $24^{*}$ & 1 & $1 / 8$ & Problem solving approach \\
\hline $24^{*}$ & 1 & $1 / 8$ & Diligence \\
\hline $24^{*}$ & 2 & $1 / 8$ & Critical thinking - how we can improve practices \\
\hline $25^{*}$ & 3 & $1 / 7$ & Independence/autonomy \\
\hline $25^{*}$ & 3 & $1 / 7$ & Self-motivation - internal driver \\
\hline 26 & 2 & $1 / 6$ & Intelligence - cognitive processing skills \\
\hline
\end{tabular}

Note. $N=18$ for the three groups combined

* Indicates equal ranking with another item(s)

\section{Insight and self-awareness}

This factor was selected by $89 \%$ of individual group members $(n=16)$, across all three groups. It was ranked as the number one most important characteristic signalling work readiness among allied health students by groups two and three, and ranked number two by group one. Insight and self-awareness achieved a particularly high aggregate mean importance ranking of 9.3 out of a maximum score of ten. Participants from all groups believed that the capacity for "insight," "self-awareness," and "the ability to self-reflect," is a key characteristic for success as an allied health professional.

I'm not surprised it's at the top. ... that's what that person needs to survive in this environment. (Grp 2)

Participants valued the ability to reflect on both task-related actions and behaviours, and on personal emotional responses to a demanding work environment. They believed that this characteristic may allow the individual opportunities to change their behaviours and improve both their performance and their coping abilities. 
... it's the ability to critically self-appraise - what did I do well and what did I not do so well, and to be able to adapt and show some initiative and be able to fix those things. (Grp 2)

Participants also articulated their belief that insight and self-awareness may be a powerful underlying characteristic that supports strengths in other areas such as emotional stability, communication, and professional behaviour.

It's one of the precursors of emotional stability. (Grp 1)

And I think it feeds into a lot of other areas as well, like that self-reflection could [influence] your professionalism or communication style, your clinical knowledge, your, like it encompasses a lot of different areas. (Grp 2)

Characteristics similar to our finding of "insight and self-awareness," labelled as "self-knowledge," "self-awareness," and "reflectiveness," have been listed among the attributes required for work readiness and employability in generic worker samples in the past; however, little mention of this characteristic could be found in the peer reviewed literature.3,9 The exception is a mention by Walker and colleagues during a revision of the Work Readiness Scale for use with graduate nurses. ${ }^{6}$ Walker states that "the personal work characteristics factor aligned with characteristics and attributes indicative of self-awareness and adaptability" (p. 636), further suggesting that the capacity for insight and self-awareness may be of interest.

\section{Resilience}

Note that resilience was used as an exemplar when introducing the Nominal Group process to participants, which may have increased the likelihood that this characteristic would be raised by group members. None the less, the extant literature has identified this characteristic as important in signalling work readiness, and therefore its presence within the top six most important characteristics in the current study is not surprising. ${ }^{5}$ Fourteen of the 18 participants in this study selected resilience as among the most important characteristics signalling work readiness among allied health students (78\%), with a mean of 8.8 , for the combined groups. Resilience was ranked the number one characteristic by group one, number two by group three, and number seven by group two.

Without resilience it's hard to do anything else ("group agrees), so, to me it's like the foundation and you can't build on anything if you don't even have resilience. (Grp 1)

Participants believed that resilience supports adaptability, flexibility (see 2.2.2), and the ability to respond helpfully to feedback, "bounce back" from challenging situations, and make any changes that need to be made.

And that ability to bounce back is the big thing about resilience, that you can get bad feedback or something you're not expecting or something can go wrong, but that doesn't crush you, that you can bounce back and learn from it and grow. (Grp 1)

"Resilience" was one of the ten categories identified in Caballero and colleagues' qualitative enquiry into work readiness among college graduates. ${ }^{5}$ This category included themes involving resilience to negative feedback, and the capacity to deal with competing work demands and challenges. Resilience is generally defined as the individual's capacity to adapt in the face of tragedy, natural disaster, health concerns, and relationship, work, or school problems. A person with good resilience can bounce back more quickly and with less stress than someone whose resilience is less developed. This capacity has clear advantages in a busy health setting, wherein health professionals are called upon to witness sometimes tragic, and often stressful events in the lives of their patients, while also carrying a significant workload and responsibility, and managing stressors in their own lives.

\section{Communication skills and adapting communication to others (verbal and written)}

Half of all group members selected communication skills as among the top seven characteristics signalling work readiness in allied health students $(n=9)$, with a very high aggregate mean score of 9.6 out of a possible 10. Communication skills were ranked number two by group two, number four by group one, and number eight by group three. Participants repeatedly raised the importance of communication skills in fostering and maintaining good relationships with both patients and team members. They recognised the importance of adapting their communication style to meet the needs of varied audiences, with a focus on building rapport.

That ability to have a relationship with your patients, your team members, that multi-disc [multi-disciplinary] team. You have to be able to adapt your communication so much between so many different environments, if you can't do that then you're not going to be able to form those professional relationships. (Grp 2) 
Strong verbal communication skills were seen by some group members as an indicator that the student would perform well in the role, across several domains.

I think any student who has strong verbal communication skills ("pause*) you know they are going to get along well with the team and get the rapport with the patients, you have some confidence they can do the job and they present well, and just function well. (Grp 3)

\section{Basic organisational skills - prioritising workload and work day organisation}

Eight group members (44\%), selected basic organisational skills as among the most important characteristics signalling work readiness, with a mean importance rating of 7.3. Possessing basic organisational skills was ranked as the number four most important characteristic by groups two and three, and number ten by group one. Group two titled this characteristic "Selfmanagement skills - prioritising workload and work day organisation," while group three focused more on reliability in their title "managing caseload/tasks; owning your day/time/products," and group one on "basic organisational skills." Participants recognised the importance of time management, effectively setting priorities and reliably completing the basic day-to-day tasks inherent in the workplace such as entering activity statistics and writing client notes in a timely manner.

Yeah just that day to day being able to plan your day, prioritise, change priorities when they need to, just getting the job done. (Grp 2)

Monitoring changeable workload priorities during the day and communicating effectively with team members to ensure work group priorities are addressed was seen as an important part of this characteristic.

And if you're struggling, then asking for help or letting somebody know if your priorities are really changing during the day and you can't keep up - which is fine, but saying that's fine too. (Grp 2)

\section{Commitment to life-long learning}

One in every three individual group members $(33 \% ; n=6)$ selected a commitment to lifelong learning as among the most important characteristics signalling work readiness among allied health students. Combined group results returned a mean importance rating of 8.5 out of a possible 10 for this characteristic. Being an active, committed lifelong learner was ranked number five most important by Group three, number seven by Group two, and number 13 by Group one. Group one labelled this characteristic "Commitment to lifelong learning", group two "active lifelong learning and intellectual curiosity", and group three "active, self-directed learner, willingness to learn." The tendency toward actively seeking to build and maintain your knowledge, prompted not by any external pressure to do so, but from a genuine curiosity and desire to improve your knowledge and skills, was highly valued.

If people are really interested about something, they'll go off on a bit of tangential reading to learn more about that. (Grp 2)

... you're working to improve yourself, and then your service and clinical practice as well. (Grp 2)

Group one members made the point that the rapidly changing nature of health information in the modern world has resulted in the need for all allied health clinicians to commit to ongoing professional reading and development to keep up with their fields.

... it's a given that the knowledge base in allied health will move forward, and that's obviously crucial then, that we need the workforce to move forward with it. (Grp 1)

\section{Professionalism}

Five of the 18 participants in these three groups selected the characteristic of professionalism as among the most important characteristics signalling work readiness among allied health students $(n=5 ; 28 \%)$. The combined data showed an average importance rating of 8.7 out of a possible 10. Professionalism was ranked number seven most important by Group three, number eight by Group one, and number 12 by Group two. While groups one and two were content to label this characteristic as "professionalism" and "professional behaviour" respectively, Group three broadened the label of this factor to "professionalism - integrity, accountability, time management, respect". This factor was seen by all groups as encompassing a broad range of professional behaviours, such as those raised in the quotes below.

Hair, nails, shoes, clothes

Interactions

Confidentiality

Being ethical 
Code of conduct

All those little things just bundled up. (Grp 2 members)

Group members were mindful that staff and students represent both their profession and the organisation for which they are working, and that this responsibility should be considered.

You represent an organisation and you act accordingly. (Grp 1)

Factors Independently Identified and Selected as Amongst the Most Important by Two of the Three Groups

A further eight characteristics were raised by group members, and subsequently voted as among the most important characteristics signalling work readiness in allied health students, by two of the three groups.

\section{Emotional stability/maturity and emotional regulation}

Group one (AH Directors) identified a characteristic labelled "Emotional stability and regulation" ( $n=4 ; \bar{x}=9.75)$. Similarly, Group three (mixed CESO group) members listed "Emotional maturity - to cope and to respond to patients" $(n=3 ; \bar{x}=8.6)$. The aggregate results for this factor $(n=7 ; \bar{x}=9.2)$, place it as number seven overall. Participants believed that the ability to tolerate emotional distress and regulate your emotions is important in providing skilled care, decision making and in meeting the emotional needs of the client.

... students and new graduates are dealing with people who are in a very vulnerable state, and so I think emotional maturity, to be able to cope with the stories that you are hearing, but also to be able to respond to the needs of the client. (Grp 3)

\section{Adaptability/flexibility}

Group one (AH Directors) identified a characteristic labelled "Adaptable to circumstances - flexible" $(n=4 ; \bar{x}=8.75)$. Similarly, Group two members (clinical supervisors) listed "Adaptability/Flexibility" $(n=2 ; \bar{x}=9)$. The aggregate results for this factor ( $n$ $=6 ; \bar{x}=8.9$ ), place it at number eight overall. Group one members raised an overlap between being flexible and able to adapt to changing circumstances and their concept of resilience ("That's resilience" Grp 1). The Clinical Supervisors making up Group two spoke about the rapidly changing demands of the work environment and the need for allied health staff to frequently and fluidly adapt to meet the needs of their clients.

... you see so many new grads struggling with that. They are set to see so many patients and these particular patients and if they can't see them it falls apart or if they need to see someone else who is a high priority and can't - you need to be flexible. (Grp 2)

\section{Empathy}

Group two members (clinical supervisors) identified a characteristic labelled "Empathy" $(n=1$; rating $=10)$. Similarly, Group three members (mixed CESO group) listed "Empathy with boundaries-appropriate sharing" $(n=2 ; \bar{x}=10)$. The aggregate results for this factor $(n=3 ; \bar{x}=10)$, place it at number nine overall. It was believed that empathy involves a genuine interest in the client, and an attempt to fully understand the client's context.

... empathy goes beyond just being aware of someone else's emotional state, it's taking a genuine interest in why they might be that way, what's actually going on for them in their world. (Grp 2)

This was seen as vitally important to building therapeutic rapport.

It might be the difference whether you connect with that person or not (Grp 2)

However, both groups raised the importance of maintaining professional boundaries with the client, despite this enhanced, empathetic understanding.

But then I think it's knowing where that line is as well and not becoming too involved. (Grp 2)

\section{Recognising stress and strategies to manage stress (self-care)}

One Group Two (clinical supervisors) member selected the "ability to manage stress" as among the most important characteristics (rating $=7$ ). Similarly, two Group Three members selected "Recognise stress and strategies to manage (selfcare)" $(\bar{x}=9)$. The aggregate results for this factor $(n=3 ; \bar{x}=8)$, place it at number ten overall. Interestingly, Group One also identified self-care on their list of important characteristics, but this item did not attract a 'most important' vote. Similarly, Group Three members identified a second, related characteristic labelled "Personal wellbeing focus - walk the talk" which focussed on the clinician's attention to their personal exercise, diet and health care routines, which did not attract a 'most 
important' vote. None the less, the identification of these additional, related characteristics by participants further strengthens the importance of stress and self-care to work readiness.

While recognising the value of being able to monitor and manage stress at all points of a allied health career, participants also acknowledged the heightened demands placed on allied health students and new graduates, and the risks this posed.

I don't know how it is with other graduates but I know psychology ones are often doing their Masters so they've got their thesis and ... case studies and a whole bunch of other stuff hanging over their necks so they've actually got a lot going on while they are trying to also do a 6-month practicum, so there's a number of skills and qualities up there that are required for them to be able to manage stress. (Grp 2)

\section{Sound technical knowledge appropriate to level of training}

One Group One (AH Directors) member selected the characteristic labelled "Sound technical and clinical knowledge related to the profession" as among the most important (rating $=8$ ). Similarly, two Group Two members (clinical supervisors) listed "Core knowledge appropriate to level of training" ( $\bar{x}=7.5)$. The aggregate results for this factor $(n=3 ; \bar{x}=7.8)$, place it as number eleven overall (equal with "Balanced confidence"). Achieving an adequate level of discipline-specific knowledge and skill to perform your role as an allied health professional would appear to be an obvious requirement for success, and this was acknowledged by both groups.

\section{That's kind of a given isn't it? (Grp 2)}

Nonetheless, it is important to note, and perhaps encouraging for trainees and new grads, that both groups qualified this requirement with the expectation that this knowledge be "appropriate to the level of training." The fact that this factor was rated number eleven overall, and not singled out as having any heightened importance by Group Three (mixed CESO group) members is also of interest.

\section{"Balanced" confidence}

Group One (AH Directors) identified a characteristic labelled "Balanced confidence" $(n=2 ; \bar{x}=9.5)$. Similarly, Group Two (clinical supervisors) members listed "Confidence - to question and discuss and to seek help" $(n=1$; rating $=6)$. The aggregate results for this factor $(n=3 ; \bar{x}=7.8)$, place it at number eleven overall (equal rank with "Sound technical knowledge"). Possessing the confidence to seek help when required, admit when you don't know, and confidently complete tasks within your level of ability, was considered a valuable asset.

... if someone needs help they need to be able to speak up about it, that's a really important trait. And also too, if they need more information, the ability to go and talk to the medical team or go and talk to the other senior $\mathrm{AH}$ clinicians without that fear. (Grp 2)

Group Two members also discussed the value of confidence when interacting with patients.

... you quite often see patients after a student and you say how are you going, how is your treatment, how was your experience with the student? And they say oh l'm not sure if he was completely believing what he was saying to me. They pick up on those things very easily I think. (Grp 2)

However, Group One members recognised that confidence needs to be appropriate to the individual's level of skill, and overreaching can be a risk rather than an asset.

I would like the students to come with confidence and be able to do the things we ask them to do without having to run away. But I also don't want them to feel so confident that they actually try to do too much or do things out of scope or, you know, go and tell the consultant they don't think they're doing a good job, or do things like that, so that they're actually causing more problems. (Grp 1)

\section{Seeking and responding to feedback \& admitting when you don't know}

One Group Two (clinical supervisors) member, and one Group Three (mixed CESO group) member, selected "Openness to seeking and responding to feedback" as amongst the most important characteristics, with importance ratings of 10 and 8 respectively. The aggregate results for this factor $(n=2 ; \bar{x}=9)$, place it as number twelve overall. Interestingly, Group One, composed of allied health directors, members identified "Openness to incorporating feedback" as an important factor, but this did not gain any votes as among the most important characteristics by this group. The ability to seek and respond to feedback in a helpful and open manner was seen as an asset to allied health professionals, and allied health students in particular.

\section{... when you're learning as a grad you're getting lots and lots of feedback. (Grp 2)}


Similar to "Balanced confidence," participants acknowledged that this involves a degree of vulnerability in the student, and that this can be challenging.

The ability to be vulnerable and admit when you don't know. (Grp 3)

Group Two clinical supervisors appreciated a student's ability to take constructive feedback in their stride, even when it is not positive, and move on with the task at hand without becoming overly fused with resultant emotions or thought.

Take it in the spirit it is intended, not being weighed down by it... that's a really important one. (Grp 2)

\section{Intrigue and interest/curiosity}

One Group Two (Clinical Supervisor) member selected "Intrigue and interest - pushing the boundaries", as amongst the most important characteristics (rating = 9). Similarly, one Group Three (mixed CESO group) member selected "Curiosity - seeking information or other approaches (interest in people and their stories)," assigning an importance rating of 8 . The aggregate results for this factor $(n=2 ; \bar{x}=8.5)$, place it at number 13 overall. Group discussions suggested that participants valued a student's ability to approach the work with curiosity and fresh eyes, in the knowledge that improvements in processes or outcomes may be achieved as a result.

... an intellectual curiosity about the work that you're actually doing which would then drive you to read a bit more or question something rather than just accept things at face value... (Grp 2)

The broad application of curiosity was thought to be of value in all aspects of the clinicians' work.

... curious from the client's point of view, or curious from that family member's point of view. So when I said curiosity, I meant that it was more than just about their learning, although that is part of it. Or even in a colleague, so seeing a colleague doing something in a certain way and saying "tell me why you did it that way", or "what was your university training like that led you to this approach, because this is how I do it and I hadn't thought about doing it from that point of view". (Grp 3)

The link between this attitude of curiosity and intrigue, when applied to individuals assigned to them for treatment, and the formation of true empathy, was also noted.

... wondering about their story, and "how does this work for you", and "what's your perspective on this, how does this feel for you". (Grp 3)

Ability to work inter-professionally

One Group One (AH Directors) member selected "[Sufficient] confidence in your own professional skills to work interprofessionally", as amongst the most important characteristics (rating $=7$ ). Similarly, one Group Two (clinical supervisor) selected "Collaborative - ability to work in inter-professional teams" (rating $=7$ ). The aggregate results for this factor $(n=2$; $\bar{x}=7$ ), place it at number 14 overall. Group members described the skills and attitudes which they believe underpin the ability to work as part of an inter-professional team, including gaining an understanding of the roles and perspectives of other health professionals, being open and accepting of these differing perspectives, and considering ways in which these differing skill sets may improve patient outcomes.

It's about getting other discipline's perspectives... (Grp 2)

So it's the ability to give up, like, ownership ...(Grp 1)

Yeah, and how can I make my practice better by understanding what everyone else does? Like, how does a psychologist talk to a client, like maybe that's a good way for me to think about how I talk to my clients? (Grp 1)

The clinical supervisors making up Group Two acknowledged the challenges inter-professional work can bring, particularly to students and new graduates.

It's quite a big change that happens very quickly where they have been with all nurses, or all with physio, or all with speech pathologists, and then all of a sudden, they want to work or they're on a clinical placement and it's like "oooh it's not just 50 physios around me here there's probably 10 different disciplines in the room, I don't know what that person does or that discipline does" (Grp 2) 
Factors Independently Identified and Selected as Amongst the Most Important by Four Members of a Single Group 2.3.1 Business Minded - Group one AH Directors

Four members of Group one (AH Directors) selected the characteristic of being "business minded" as among the most important characteristics signalling work readiness in allied health students $(\bar{x}=8.5)$. This characteristic was subsequently ranked number six in the Group one data, and number 15 in the aggregated list of 37 important characteristics identified in the study. The allied health directors making up this group recognised that clinicians, and particularly new or trainee clinicians, can become focussed on the needs of an individual patient without due awareness of the bigger-picture organisational realities that surround their work. Given today's significant economic restrictions on health care expenditure, there are unavoidable pressures on clinicians to provide a service which is both effective and efficient. The onus is on all staff to facilitate service delivery within budget, and to avoid lengthy delays in health care access to the broader community, by efficiently treating clients and discharging without undue delay.

... clinicians struggle between that desire to help people and provide that service, but also understanding that it's got to be an efficient service. (Grp 1)

This group of Allied Health Directors recognised that their awareness of the need to be 'business minded' to work effectively in the health service had grown as a result of their management experience within the organisation.

I think that business minded stuff has probably come up for us because for me, being a Director, it's something that l've had to learn - like to have that language and that understanding because now we're constantly talking to the clinicians about it ... (Grp 1)

\subsubsection{Sense of Humour - Group three CESO/Clinical Supervisor mixed group}

Four members of Group three selected sense of humour as among the most important characteristics $(\bar{x}=8)$. This characteristic was ranked third in the group three results, and sixteenth overall. While the group labelled this characteristic "Sense of humour" they made it clear that this included broader attitudes and behaviours such as being friendly and approachable.

Playfulness, friendliness, approachability... (Grp 3)

I think it is someone who is collegial...who is a positive person to work with, who creates a positive culture in your teams. (Grp 3)

Factors Independently Identified and Selected as Amongst the Most Important by Three Members of a Single Group 2.4.1 Enthusiasm

Three members of group two (Clinical Supervisors) selected "Enthusiasm" as among the most important characteristics $(\bar{x}$ $=8.3$ ). This characteristic was ranked third in the Group two results, and seventeenth overall. Group two members described approaching the work with an attitude of enthusiasm.

Look like they want to be here. (Grp 2)

These clinical supervisors recognised that students will sometimes be allocated placements which are disappointing to them in some way. Despite efforts to meet everyone's preferences, this can be unavoidable and happens relatively frequently. Staff or students who can adapt to these disappointments and maintain enthusiasm for the task at hand are at an advantage.

We've had some interesting experiences where students have come for project placements and it's maybe not quite been what they expected and you know, the ones that have shone and run with that showed the enthusiasm. (Grp 2)

\subsubsection{Clinical Reasoning}

Three members of group two (Clinical Supervisors) selected "Clinical reasoning" as among the most important characteristics $(\bar{x}=7.7)$. This characteristic was ranked third in the group three results, and eighteenth overall. Clinical reasoning involves thinking through the various aspects of patient care to arrive at a reasonable decision regarding the prevention, diagnosis, or treatment of a clinical problem in a specific patient. The Clinical Supervisors making up Group two recognised that knowledge of the discipline is important in supporting this reasoning, and in particular, the student's ability to grasp theories and models underpinning their work. 
I guess it seems they're applying what they've learnt so again it's back to knowledge, but then applying it in a practical way and that they're understanding some of the theory and models and things that they've learnt at uni. (Grp 2)

\section{Factors Independently Identified and Selected as Amongst the Most Important by Two Members of a Single Group Growth mindset}

Two members of Group One (AH Directors) selected having a "Growth mindset" as among the most important characteristics signalling work readiness in allied health students $(\bar{x}=9.5)$. This characteristic was subsequently ranked equal seventh in the Group One data (equal ranking with "Balanced confidence"), and number 19 overall. Having a "growth mindset" was described by the Allied Health Directors group as involving an energy and passion for the work and the ability to embrace positive changes.

Action focussed, passionate - all that. It's probably tied up a bit in lifelong learning, and all those things that make you bigger and better. (Grp 1)

Openness to change. (Grp 1)

\section{Understanding contexts}

Two members of Group One (AH Directors) identified "understanding contexts" as among the most important characteristics signalling work readiness in allied health students $(\bar{x}=9)$. This characteristic was subsequently ranked equal eighth in the Group One data (equal ranking with "Professionalism"), and number 20 (equal with Group Three's "Sound, stable personality constructs") overall. This factor highlights the varied contexts which exist in the health service such as communicating with senior staff or management, peers, members of different professions, stakeholders including family members, and patients. Such interactions will also be impacted by varied situational contexts such as tea room discussions, formal meetings, routine interactions on the ward, or high stress situations such as patient health emergencies. The health professional is called upon to flexibly alter their communication style and other behaviours to best meet the needs of a sometimes rapidly changing work context.

That's about changing behaviour to the contexts you're in. (Grp 1)

\section{Sound, stable personality constructs}

Two members of Group Three (mixed CESO group) identified "Sound, stable personality constructs" as among the most important characteristics signalling work readiness in allied health students $(\bar{x}=9)$. This characteristic was subsequently ranked equal seventh in the Group Three data (equal ranking with "Recognise stress and strategies to manage (self-care)"). Sound, stable personality constructs was ranked number 20 (equal with Group One's "Understanding contexts"), overall. Group Three members had a lengthy discussion exploring the need for sound, stable personality constructs in allied health clinicians and students.

As a clinician, we have to have some sort of soundness, an un-fragmented and stable personality ourselves in order to do the work that we do. And students especially because they're in a state of just, learning and being a bit vulnerable, and they need to have a bit of guidance. (Grp 3)

This was seen as important both in direct clinical work, and in facilitating clinical teamwork.

Even just to get along with other staff members - be part of the team. How many teams just fall apart because of personality stuff? (grp 3)

When the staff member or student becomes emotionally dysregulated or unstable due to personality constructs, this was seen to have a significant impact on both patients and staff.

But if they're not able to be contained even within themselves then sort of - they're not ready to be within a work team and ... Dealing with vulnerable people. (Grp 3)

Group members recognised the inherent difficulties in assessing and managing staff and students whose personality constructs may be a barrier to the smooth and efficient running of the health service. They acknowledged that these characteristics exist on a continuum and that action need not be taken unless the clinician's work is being affected.

That's difficult though because we're all on that continuum somewhere, because we're all people. So it would be around challenging when it then affected somebody's ability to practice their profession, and that could go up and down too ... (Grp 3) 
Group members believed that universities may have a role to play in acting as gate-keepers to ensure students have the capacity to perform in busy, high-stress clinical environments early in their training.

That's a conversation that perhaps we can have with universities because they can be the gatekeepers for that sometimes ... (Grp 3)

\section{Desire for continuous improvement - able to stop and review}

Two members of Group One (AH Directors) identified "Desire for continuous improvement - able to stop and review" as among the most important characteristics signalling work readiness in allied health students $(\bar{x}=8)$. This characteristic was ranked ninth in the Group One data, and number 21 overall. The allied health directors making up group one valued the individual's drive toward continuous improvements in the health service and health care delivery, an aspect of the current characteristic which may overlap with Group One's "Growth mindset" (2.5.1). However, discussions around "Desire for continuous improvement - able to stop and review" reveal a specific focus here on pausing periodically to skilfully evaluate current services with a view to making regular, sometimes apparently minor, changes that may lead to meaningful service improvements.

Service improvement - The skills to be able to know what you're measuring. (Grp 1)

\section{Factors Identified and Selected as Amongst the Most Important by a Single Participant Only}

There were 14 factors which were identified by one group only and selected as among the most important characteristics by one participant only. The assigned meaning of many of these overlap with characteristics raised elsewhere. However, the data does not support their combination into equivalent characteristics, but rather suggests that some characteristics described may be complex and inter-related. These 14 factors fell into five broad groups, including:

1. Cognitive Factors

a. Critical thinking (Gp 3; Rating 10)

b. Problem solving approach (Gp 1; Rating 8)

c. Critical thinking - how we can improve practices (Gp 2; Rating 8)

d. Intelligence - cognitive processing skills (Gp 2; Rating 6)

2. Team versus independent practice

a. Team focus/team player (Gp 1; Rating 10)

b. Independence/autonomy (Gp 3; Rating 7)

3. Utilising initiative

a. Considered initiative (Gp 1; Rating 10)

b. Self-initiation (Gp 2; Rating 10)

4. Individual values

a. Mindset for contribution to service (Gp 1; Rating 10)

b. Patient focus/values (Gp 3; Rating 10)

c. Self-motivation - internal driver (Gp 3; Rating 7)

5. Other personal characteristics
a. Optimism (Gp 1; Rating 9)
b. Personable (Gp 2; Rating 9)
c. Diligence (Gp 1; Rating 8)

\section{Final Reflections Provided by Participants}

At Step Six of the Nominal Group process, participants were invited to reflect on the groups' results and provide any additional insights or comments which may further illuminate their response to the research question under consideration. When considering their group results, group members were frequently struck by how many of the characteristics thought to be of most importance among individuals entering the allied health professions were not considered a routine part of their training in preparing them for these roles.

A lot of this stuff isn't really around curriculum, a lot of this stuff is personal...and prior to curriculum and curriculum learning. I think of lot of this stuff is enhanced by exposure of students to the workplace. I think the workplace becomes a really important role model for it... but yeah...it isn't something that comes out of a book or out of the university course ...so it's very interesting in that way. (Grp 3)

Participants also acknowledged the potentially challenging outcomes for students/allied health professionals and the organisation when these characteristics are lacking. 
... we've actually had to stop someone's placement - I think in week two - because they just couldn't get it [professionalism]. (Grp 1)

I think the biggest problem as a manager is, if someone gets into the organisation without those things, then they're very hard to get out of it. ("group agrees) And as soon as you get down the track of emotional instability and stuff, from a HR perspective they're so ... they want to steer away from it completely ... (Grp 1)

\section{CONCLUSION AND IMPLICATIONS}

This study utilised the skills and insights of allied health directors, experienced clinical supervisors, and clinical educators to identify the personal characteristics thought to be most important in signalling work readiness among allied health students. Analysis revealed six characteristics which were identified and voted as among the most important by members of each independent group. Personal insight and self-awareness rose to the top of the list of most important characteristics, with 16 of the 18 participants voting for this characteristic, with a mean importance rating of 9.3 of a possible 10 . Resilience was second on this list, followed by communication skills, organisational skills, lifelong learning, and professionalism. A further nine characteristics were selected by two of the three groups, while an additional 22 characteristics were raised and voted as among the most important by members of a single group.

Overall, it is interesting to note the preponderance of very personal, personality-based and/or emotion-focussed characteristics raised in this study. This overarching theme was evident in the data from all three groups. Examples include insight and selfawareness, resilience, emotional stability, adaptability, empathy, stress management, curiosity, enthusiasm, and sound, stable personality constructs. Characteristics such as these may provide some challenges for allied health managers and clinical education staff who hope to assist students entering the profession and/or being recruited into the health service to further develop these characteristics.

While not the focus of this study, it is also interesting to note the differences and similarities between characteristics identified by each separate group, representing differing allied health roles within the health service. The allied health directors making up Group One identified several characteristics associated with service improvements which were not raised by other groups, such as being "Business minded", having a "Growth mindset" and the "Desire for continuous improvement." This is not surprising given the broader, district-wide management context of these positions. In fact, one AH director participant commented that she had only truly learned to appreciate the importance of these characteristics since being employed in this role.

Group Two was comprised of experienced clinical supervisors. These staff members are responsible for the day to day supervision, mentoring and training of students on placement and as such may spend more time with the student than other staff involved in supporting placements. They are also typically responsible for observing and assessing the student's clinical work. Results for this group were more likely to overlap with those of other groups, with eight of the nine characteristics voted as important by two groups being shared with Group Two. Two of the six Group Three places were filled by clinical supervisors due to the difficulties populating this group, which may explain some of this overlap.

Clinical educators, who made up four of the six members of Group Three, are responsible for supporting students and supervisors during placement, including problem solving issues around placement management, demonstration of competence and the supervisory relationship. In addition to insight and resilience, this group recognised the need for emotional maturity, stress management and a sense of humour in their ranking of important work readiness characteristics.

Groups One (directors) and Three (clinical educators) were the least similar in their responses, with only one of the nine twogroup results representing an overlap between these two groups (emotional stability/regulation). Clinical supervisors and allied health directors shared the belief that adaptability, clinical and technical knowledge, confidence, and the ability to work interprofessionally were important. Clinical supervisors and clinical educators shared a focus on empathy, stress management, the ability to respond well to feedback, and curiosity as important characteristics in students.

These personal characteristics may have implications for the work readiness of allied health graduates entering the workforce. As such, the DDH Clinical Education Team plan to explore options to foster and/or enhance these characteristics in students completing placements within the district. These insights may also be of interest to allied health students, staff, recruiters and managers. It is hoped that universities and training organisations may also utilise these insights and consider the possible benefits of screening for and/or developing these characteristics in allied health students. 


\section{REFERENCES}

1. Casner-Lotto J, Barrington L. Are they really ready for work? Employer' perspectives on the basic knowledge and applied skills of new entrants to the 21st century US workforce 2006 [accessed 2018, 25 September]. Available from: http://www.p21.org/storage/documents/FINAL_REPORT_PDF09-29-06.pdf.

2. Gardner PD, Liu WY. Prepared to perform? Employers rate work readiness of new grads. Journal of Career Planning \& Employment. 1997;57(3):32-56.

3. Hart P. How should colleges assess and improve student learning? Employers' views on the accountability challenge. A survey of employers conducted on behalf of: The Association of American Colleges and Universities. Washington, DC: The Association of American Colleges and Universities, Associates PDHR; 2008.

4. Cabellero $\mathrm{CL}$, Walker $\mathrm{A}$. Work readiness in graduate recruitment and selection : a review of current assessment methods. Journal of Teaching and Learning for Graduate Employability. 2010;1(1):13-25.

5. Caballero CL, Walker A, Fuller-Tyszkiewicz M. The Work Readiness Scale (WRS): Developing a measure to assess work readiness in college graduates. Journal of Teaching and Learning for Graduate Employability. 2011;2(2):41-54.

6. Walker A, Storey KM, Costa BM, Leung RK. Refinement and validation of the Work Readiness Scale for graduate nurses. Nursing Outlook. 2015;63(6):632-8. [PMID: 26210943]

7. Walker A, Yong M, Pang L, Fullarton C, Costa B, Dunning AM. Work readiness of graduate health professionals. Nurse Education Today. 2013;33(2):116-22. [PMID: 22336479]

8. Delbecq AL, Van De Ven AH, Gustafson DH. Group Techniques for Program Planning: A Guide to Nominal Group and Delphi Processes. Dallas, USA: Scott-Foresman 1975.

9. Knight PT, Yorke M. Assessment, learning and employability. Berkshire: McGraw Hill Education; 2003. 